\title{
The inhibitory effect of flavonoids on
}

\section{interleukin-8 release by human gastric adenocarcinoma (AGS) cells infected with cag PAI (+) Helicobacter pylori}

\author{
MARIUSZ A. SKIBA, KORNELIA SZENDZIELORZ, BOGDAN MAZUR, WOJCIECH KRÓL
}

Department and Chair of Microbiology and Immunology, Medical University of Silesia, Zabrze, Poland

\begin{abstract}
Introduction: It is well known that the presence of Helicobacter pylori in the stomach induces gastritis and causes an immune response. Exposure of gastric epithelial cell lines to this germ induces the secretion of interleukin-8 (IL-8), which is a potent PMN-activating chemotactic cytokine. Interleukin-8 is usually elevated in gastric biopsy samples of patients with $\mathrm{H}$. pylori-associated gastritis and significantly increases in the supernatant of in vitro cultivated biopsy samples of gastric mucosa with active H. pylori gastritis. Interleukin-8 is an activating factor for leucocytes and other pro-inflammatory factors, free radicals, and proteolytic enzymes. That is why natural compounds potentially useful in therapy are still investigated - among them flavonoids. They reveal anti-oxidative and anti-inflammatory activities and significantly inhibit the gastric mucosa damage.

The aim of the study was the estimation of the anti-inflammatory effects of flavonoids on H. pylori-induced activation of human gastric adenocarcinoma cells (AGS). After infection of AGS cells by cag $P A I(+) H$. pylori in vitro, secretion of IL-8, effects of flavonoids on viability of AGS cells, and effects of flavonoids on increase of $H$. pylori were determined. Such flavones as chrysin, quercetin, kaemferide, flavanone, galangin, and kaempferol were examined.

Results: This study has shown an inhibitory effect of flavonoids on the release of IL-8 through infected AGS cells (except chrysin), and no toxic effects to AGS cells were observed. Galangin revealed antibacterial effects against $H$. pylori. Flavonoids limit the inflammatory process through the inhibition of IL-8 release in infected AGS cells with H. pylori. The strongest inhibitor of IL-8 was galangin.
\end{abstract}

Key words: H. pylori, interleukin-8, flavonoids, inflammation, AGS cocultures.

(Cent Eur J Immunol 2016; 41 (3): 229-235)

\section{Introduction}

Infection with the human gastric pathogen Helicobacter pylori can develop into chronic gastritis, peptic ulcer, gastric cancer, and gastric B-cell lymphoma [1-6]. In their early reports, Warren and Marshall noted a characteristic incrementation of polymorphonuclear neutrophil leukocytes near gastric mucosal epithelium; moreover, neutrophil infiltration of the gastric epithelium has been proposed as the initial pathologic abnormality and histologic hallmark of active $H$. pylori gastritis $[2,6,7]$. This Gram-negative spiral-shaped microaerophilic bacteria colonises the gastric mucosa and induces the expression of variable pro-inflammatory cytokines, such as, tumour necrosis factor $\alpha$ (TNF- $\alpha$ ), interleukin (IL)-1 $\beta$, IL-2, IL-6, IL-12, and especially IL-8, interferons $\alpha, \beta$, and $\gamma$, granu- locyte-macrophage colony stimulating factor (GM-CSF), monocyte chemoattractant protein 1 (MCP-1) in vitro, and many others, which stimulate neutrophil migration along a chemotactic gradient and modulate neutrophil adhesion molecule expression $[4,8,9]$. Nuclear factor- $\kappa \mathrm{B}$ $(\mathrm{NF}-\kappa \mathrm{B})$ is an important ubiquitous transcription factor, which is involved in the activation of a wide variety of immune or inflammatory responses by regulating the expression of genes encoding pro-inflammatory cytokines and chemokines [4, 8, 9]. Helicobacter pylori has been shown to indicate the activation of $N F-\kappa B$ in human gastric cancer cell lines, which is followed by increased pro-inflammatory cytokine expression $[4,7,9]$. Adherence is considered to be associated with both the colonisation and virulence properties of $H$. pylori. The strains can be divided into two major groups: one in which both a 128

Correspondence: Mariusz A. Skiba, MD, PhD, Department and Chair of Microbiology and Immunology Medical University of Silesia, Jordana 19, 41-808 Zabrze, Poland, e-mail: mskiba@sum.edu.pl Submitted: 29.11.2015; Accepted: 18.03.2016 
$\mathrm{kDa}$ antigen (cytotoxin-associated gene $\mathrm{A}-\mathrm{CagA}$ ) and vacuolating cytotoxin ( $\mathrm{VacA}$ ) are expressed, and another that does not produce these proteins [10]. CagA protein is a marker for the presence of the cag pathogenicity island (PAI), a fragment of chromosomal DNA that encodes c. 30 genes [11]. Helicobacter pylori strains expressing the CagA protein and strongly associated vacuolating cytotoxin induce IL-8 secretion from gastric epithelial cells, but minimal secretion occurs after culture with non cytotoxic CagA negative strains $[10,11]$. For this reason cag PAI(+) strains were used in this study. The host responses to H. pylori infection seem to be critical in ulcer genesis, such as disturbance of the delicate balance between protecting and damaging factors [11]. The sequence of inflammation depends on balance between different pro-inflammatory and anti-inflammatory (IL-4, IL-10) cytokines released due to infection [5, 7, 9-11]. Prolonged IL-8 production by gastric epithelial cells during $H$. pylori infection could result in the activation and recruitment of neutrophils and lymphocytes to infected tissues and therefore play a role in the immunopathogenesis of $H$. pylori infection [12]. Activated inflammatory cells produce many pro-inflammatory factors, proteolytic enzymes, and free radicals, which leads to tissue damage [13-15]. Currently, triple therapies consisting of two antibiotics and a proton pump inhibitor show high eradication rates [16]. However, still some problems remain. Helicobacter pylori rapidly acquires resistance to some antibiotics. Therefore, a new antibacterial agent that is both highly effective and safe, is required for the treatment of $H$. pylori infection. It has been reported that various medicinal plant extracts such as flavonoids have antibacterial and/or anti-inflammatory activity [17]. Flavonoids are natural, biologically active substances extracted from many plants. They possess potent anti-inflammation, anti-cancer, and anti-oxidation properties. All flavonoids possess similar chemical structure but they cause a very large spectrum of different biological effects. The anti-aggregation effect on platelets and tightening effect of flavonoids on vessels has been proven. They also demonstrate an antibacterial effect on different germs, including multi-resistant strains. An additional advantage of flavonoids is their very low toxicity and synergetic effect with antibiotics. Those substances inhibit cyclooxygenase and phosphodiesterase and demonstrate an anti-atherosclerotic effect. They can reduce damaging effects of ischaemia-reperfusion phenomenon and take a part in hepatoprotection. Currently its anti-cancer activity is being intensively investigated. Flavonoids in combination with cytokines and chemotherapy (flavone acetic acid - FAA) can modify immunological response, stimulate production of different cytokines (e.g. IL-1, IL-2, and TNF- $\alpha$ ), and inhibit protein kinase $\mathrm{C}$ and tyrosine kinase [18]. A very important characteristic of flavonoids is their anti-inflammatory action. They inhibit leukotriene $\mathrm{B}_{4}$ $\left(\mathrm{LTB}_{4}\right)$ and prostaglandin $\mathrm{E}_{2}\left(\mathrm{PGE}_{2}\right)$ production as well as cyclooxygenase-2 expression [19]. Another mechanism of anti-inflammatory effect is suppression of pro-inflammatory cytokines release. They are also natural scavengers. Our own researches have shown that flavonoids are very potent macrophage and neutrophil chemiluminescence inhibitors [20-22]. Flavone derivatives also reduce neutrophils' nitric oxide generation. Some authors indicate its direct anti-bacterial activity on $H$. pylori (flavone, flavanone, quercetin, genistein, irysquinone).

The aim of the study was the estimation of the anti-inflammatory effects of flavonoids on $H$. pylori-induced activation of human gastric adenocarcinoma (AGS) cells. After infection of AGS cells by cag PAI (+) H. pylori in vitro, secretion of IL-8, the effects of flavonoids on viability of AGS cells, and the effects of flavonoids on the increase of $H$. pylori were determined. Such flavones as chrysin, quercetin, kaempferide, flavanone, galangin, and kaempferol were examined.

\section{Material and methods}

In the study AGS cell line was used (American Type Culture Collection, CRL-1739 - Manassas, VA, USA). Cell cultures were infected with cag PAI positive $H$. $p y$ lori (CCUG 17874 - Deutsche Sammlung von Microorganismen und Zellkulturen; no. 4867 - Braunschweig, Germany). The following flavone derivatives were examined: flavone (2-fenylo-4H-1-benzopirone-4-on), chrysin (5,7-dihydroxyflavone), quercetin (3,3',4',5,7-pentahydroxyflavone), kaempferide (3,5,7-trihydroxy-4'-metoxyflavone), flavanone (2,3-dihydroflavone) (Serva Feinbiochemica - Heidelberg, Germany), galangin (3,5,7-trihydroxyflavone) (Aldrich Chemical Company, Milwaukee, WI, USA), and kaempferol (3,4',5,7-tetrahydroxyflavone) (Sigma Chemical Company, St. Louis, MO, USA). Cells were maintained in an atmosphere of 5\% $\mathrm{CO}_{2}$ at $37^{\circ} \mathrm{C}$ in $\mathrm{F} 12 \mathrm{~K}$ medium (Vitacell, ATCC, Manassas, VA, USA) supplemented with $10 \%$ foetal bovine serum (Bio-Whittaker, Walkersville, MD, USA), $100 \mathrm{U} / \mathrm{ml}$ penicillin, and $100 \mu \mathrm{g} / \mathrm{ml}$ streptomycin (Gibco BRL Life Technologies, Paisley, UK). The cells were cultured in 50 and $500 \mathrm{ml}$ plastic flasks (Nunc A/S Rosklide, Denmark) and passaged three times a week (continuous cell culture). Cell viability was determined by trypan blue (Sigma Chemical Company, St. Louis, MO, USA). The concentration of cell suspension used was $10^{6}$ cells $/ \mathrm{ml}$. Cells were seeded and cultured to confluence. Then, monolayers were treated with increased concentrations of tested compounds. Helicobacter pylori were grown on Columbia agar plates (Bio Merieux, Marcy l'Etoile, France) supplemented with $6 \%$ sheep blood at $37^{\circ} \mathrm{C}$ under microaerophillic conditions $\left(85 \% \mathrm{NO}_{2}, 10 \% \mathrm{CO}_{2}, 5 \% \mathrm{O}_{2}\right)$ generated with a Genbox microaer (Bio Merieux) using an anaerobic chamber. The flavone derivatives were dissolved in DMSO and added to cell cultures in concentrations as follows: $15 \mu \mathrm{M}$, 
$30 \mu \mathrm{M}$, and $60 \mu \mathrm{M}$. Human gastric adenocarcinoma cells were incubated with dissolved flavonoids for over 16 hours $\left(5 \% \mathrm{CO}_{2}, 37^{\circ} \mathrm{C}, 100 \%\right.$ humidity). Flavonoids dissolved in DMSO and diluted with culture medium (Brain Heart Infusion) were added to bacterial suspensions $\left(10^{6} \mathrm{CFU} /\right.$ $\mathrm{ml}$ ) in the following concentrations: $30 \mu \mathrm{M}, 60 \mu \mathrm{M}$, and $90 \mu \mathrm{M}$. The final concentration of DMSO was adjusted to $0.1 \%$. The control plates contained medium alone and medium plus DMSO. The control AGS and bacteria received the same amount of DMSO. After incubation under microaerophillic conditions the growth inhibition of bacteria was determined by turbidimetric method (+ homogenous suspension, ++ low grade of bacterial turbidity, +++ high grade of turbidity). Bacterial suspensions were added also to AGS cultures in the following proportions: $10: 1 \mathrm{CFU} /$ AGS cells, $50: 1 \mathrm{CFU} / \mathrm{AGS}$ cell, $100: 1 \mathrm{CFU} / \mathrm{AGS}$ cells, and $500: 1 \mathrm{CFU} / A G S$ cells. Cell vitality was determined by trypan blue. In order to perform other determinations $100: 1 \mathrm{CFU} / \mathrm{AGS}$ cells were used. The concentration of IL-8 in culture supernatants infected with $H$. pylori in the presence of flavonoids or their absence, was quantitated by ELISA method (R and D Systems Minneapolis, MN, USA), using human recombinant IL-8 as a standard, following the manufacturer protocol. The absorbance values were measured at $450 \mathrm{~nm}$. This assay has a sensitivity of detection less than $10 \mathrm{pg} / \mathrm{ml}$. All obtained values are expressed as means $\pm \mathrm{SD}$. Student unpaired $t$-test was used to asses the statistical significance of differences. Data were verified with $\chi^{2} . P<0.05$ was set as the level of statistical significance.

\section{Results}

No toxic effect of any of the flavone derivatives investigated (in concentrations between 30-60 $\mu \mathrm{M}$ ) after 16 hours of incubation with AGS cells was observed. Viability of investigated cells was more than $95 \%$. Maximum AGS viability incubated with investigated flavonoids was

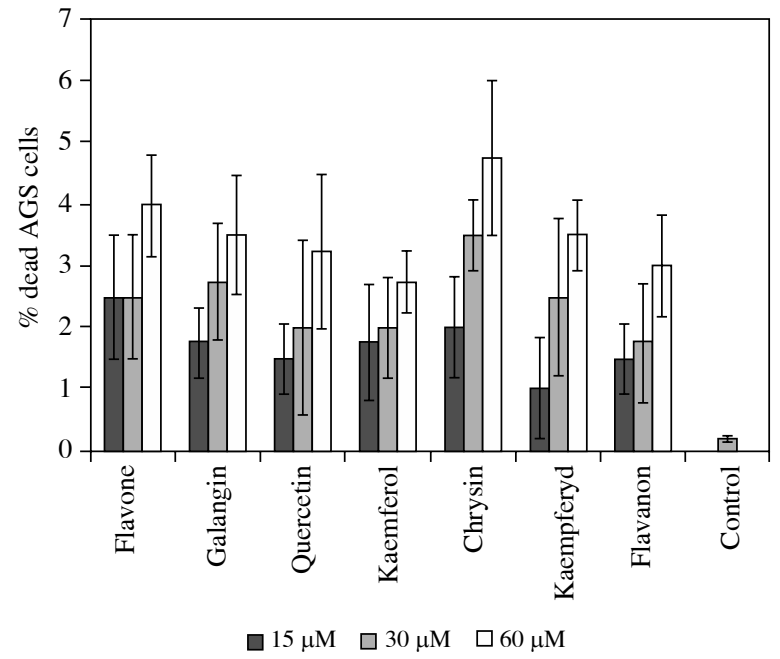

Fig. 1. Flavone derivatives toxicity effect on AGS cell lines after 16 hour incubation

observed at a concentration of $15 \mu \mathrm{M}$ and was between $97.5 \%$ for flavone and $99 \%$ for kaempferide. The greatest quantity of dead cells was determined in AGS cultures incubated with chrysin $(60 \mu \mathrm{M})$. The viability in this case was $95.25 \%$ (Fig. 1).

Galangin showed the strongest anti-bacterial action against $H$. pylori in concentrations of $60 \mu \mathrm{M}$ and $90 \mu \mathrm{M}$, whereas flavone and kaempferide showed a similar effect in $90 \mu \mathrm{M}$ concentration. Significantly lower anti-bacterial effect of other investigated flavonoids was observed (Table 1).

The concentration of IL-8 in culture supernatants was measured by ELISA. Uninfected AGS cells after 16 hours incubation in medium alone produced background levels of IL-8 (57.8 $\pm 8.0 \mathrm{pg} / \mathrm{ml})$. No significant increase of IL-8 in supernatants from AGS cells incubated with different concentrations of investigated flavonoids was observed. Whereas after $H$. pylori infection $100: 1 \mathrm{CFU}$ (colony forming units)/AGS cells, AGS cells produced increased

Table 1. Bacterial turbidity in the presence of flavone derivatives

\begin{tabular}{|c|c|c|c|c|c|}
\hline Flavon derivative & Concentration $(\mu \mathrm{m})$ & Bacterial turbidity & Flavon derivative & Concentration $(\mu \mathrm{M})$ & Bacterial turbidity \\
\hline \multirow[t]{3}{*}{ Flavone } & 30 & +++ & Kaempferol & 30 & +++ \\
\hline & 60 & +++ & & 60 & +++ \\
\hline & 90 & +++ & & 90 & +++ \\
\hline \multirow[t]{3}{*}{ Chrysin } & 30 & +++ & Kaemferyd & 30 & +++ \\
\hline & 60 & +++ & & 60 & +++ \\
\hline & 90 & +++ & & 90 & ++ \\
\hline \multirow[t]{3}{*}{ Galangin } & 30 & +++ & Quercetin & 30 & +++ \\
\hline & 60 & ++ & & 60 & +++ \\
\hline & 90 & ++ & & 90 & +++ \\
\hline \multirow[t]{3}{*}{ Flavanone } & 30 & +++ & Control & 0 & +++ \\
\hline & 60 & +++ & & & \\
\hline & 90 & ++ & & & \\
\hline
\end{tabular}


the amount of IL-8 $(894.6 \pm 58.9 \mathrm{pg} / \mathrm{ml})$. To estimate the inhibitory effect of flavonoids the percentage of inhibition ratio was calculated.

Percentage of inhibition ratio $=[(\mathrm{K}-\mathrm{I}): \mathrm{K}] \times 100 \%$ where: $\mathrm{K}$ - control value; I - IL-8 release

All investigated derivatives except chrysin showed their inhibitory effect on IL-8 release by infected AGS cells. Galangin was the strongest inhibitor of IL-8. This effect was proportional to its increased concentration $(p<0.001)$ and amounted to $690.5 \pm 33.1 \mathrm{pg} / \mathrm{ml}$ of IL-8 for $15 \mu \mathrm{M}$ of galangin and it was $22.8 \%$ of the IL- 8 inhibition ratio, whereas a $60 \mu \mathrm{M}$ solution of galangin decreased IL- 8 release to $251.6 \pm 5.8 \mathrm{pg} / \mathrm{ml}$ and it was $71.9 \%$ of the IL-8 inhibition ratio (Fig. 2). Flavone and flavanone showed a slightly lower inhibitory effect

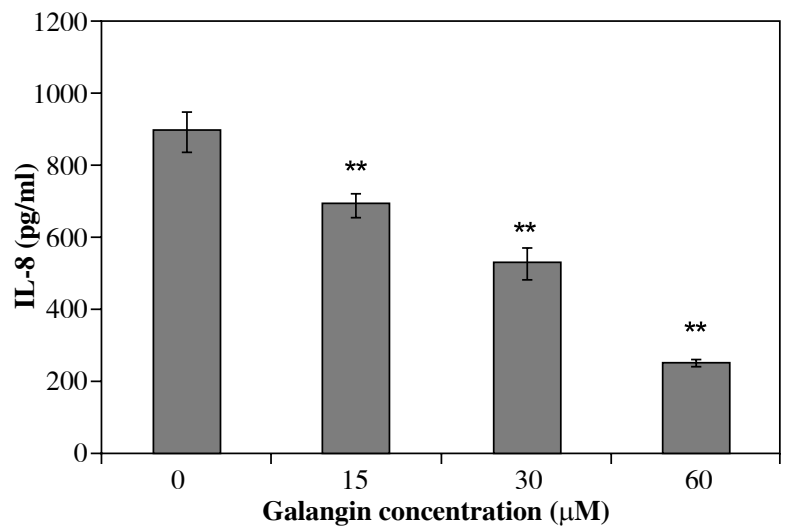

Fig. 2. Interleukin-8 release by AGS cells infected with H. pylori incubated with galangin. Results shown as mean $\pm \mathrm{SD}(* * t$-Student test, $p<0.001)$

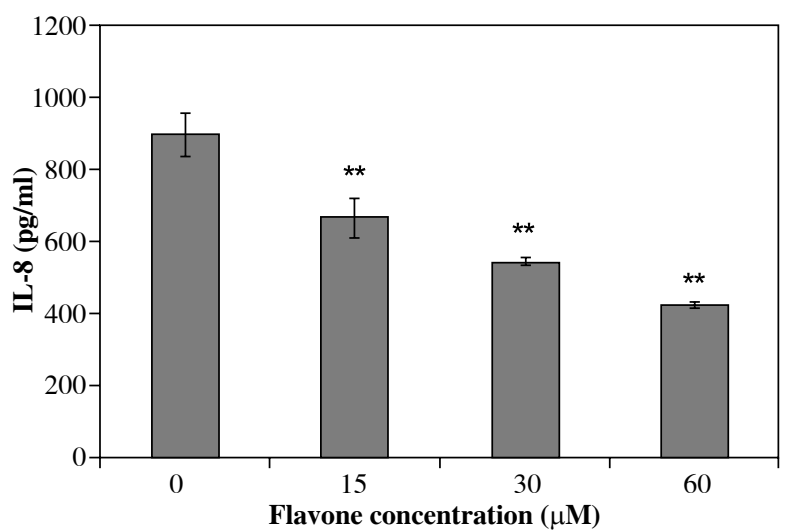

Fig. 4. Interleukin-8 release by AGS cells infected with H. pylori incubated with flavone. Results shown as mean $\pm \mathrm{SD}(* * t$-Student test, $p<0.001)$
(25.2-52.7\% inhibition of IL-8 ratio) (Figs. 3, 4). Quercetin and kaempferol inhibited IL-8 release at the same level in all concentrations used $(\%$ of inhibition ratio respectively: $28.0-42.9 \%$; $p<0.001$ ) (Figs. 5, 6). Kaempferide showed the strongest inhibitory effect in $60 \mu \mathrm{M}$ concentration $(572.4 \pm 28.5 \mathrm{pg} / \mathrm{ml}$ of IL-8, and it was $36.6 \%$ of the inhibition ratio) (Fig. 7). Only chrysin independently of concentration significantly increased IL-8 release from infected AGS cells $(p<0.05)$ (Fig. 8). The results obtained were: $1023 \pm 14.8 \mathrm{pg} / \mathrm{ml}$ of IL- 8 for $60 \mu \mathrm{M}$ concentration of chrysin $(894.6 \pm 58.9 \mathrm{pg} / \mathrm{ml}$ for unstimulated control).

\section{Conclusions}

This study has shown the inhibitory effect of investigated flavone derivatives (except chrysin) on release of

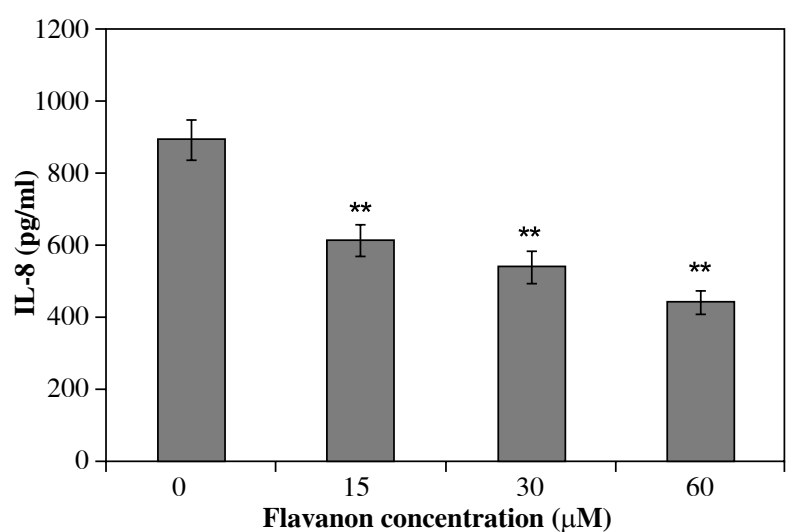

Fig. 3. Interleukin-8 release by AGS cells infected with H. pylori incubated with flavanon. Results shown as mean $\pm \mathrm{SD}(* * t$-Student test, $p<0.001)$

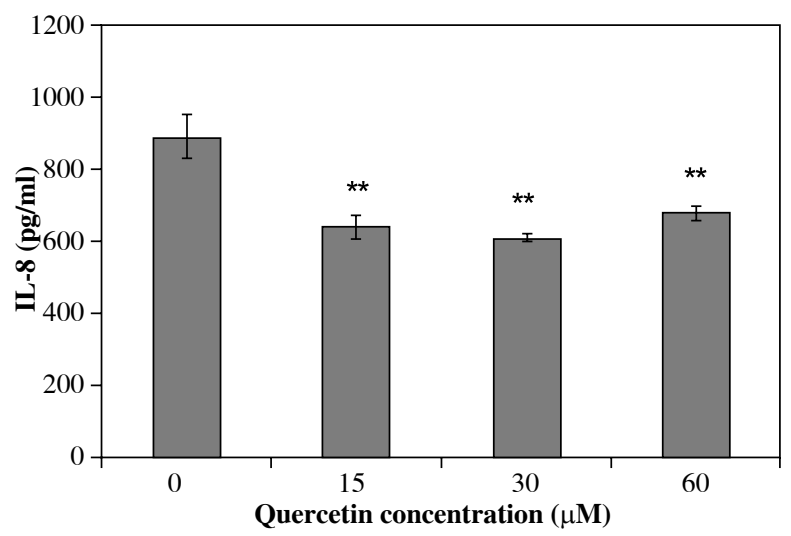

Fig. 5. Interleukin-8 release by AGS cells infected with H. pylori incubated with quercetin. Results shown as mean $\pm \mathrm{SD}(* * t$-Student test, $p<0.001)$ 


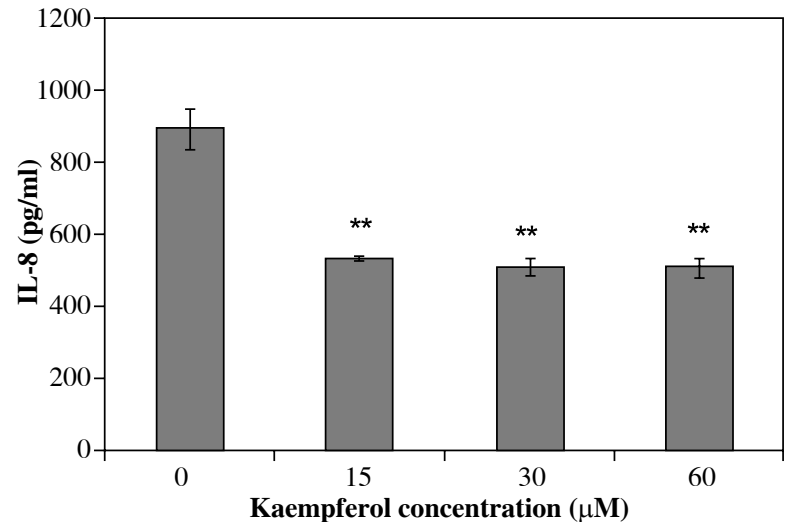

Fig. 6. Interleukin-8 release by AGS cells infected with H. pylori incubated with kaempferol. Results shown as mean $\pm \mathrm{SD}(* * t$-Student test, $p<0.001)$

IL-8 through infected AGS cells with cag PAI-positive strains of $H$. pylori. No toxic effects to AGS cells were observed. Galangin revealed an antibacterial effect against H. pylori. Flavonoids could limit the inflammatory process through the inhibition of IL-8 release by infected AGS cells. The strongest inhibitor of IL-8 secretion was galangin.

\section{Discussion}

Helicobacter pylori infects more than $50 \%$ of the world's population and has been shown to be an important pathogen of gastro-duodenal inflammation, gastric carcinoma, and gastric B-cell lymphoma [7, 9, 11, 23]. In this study a cag PAI-positive strain of $H$. pylori was used. Earlier research has shown that activated gastric epithelial cells can release great amounts of pro-inflammatory chemokines and cytokines, especially IL-8 [15]. The cytokines are responsible for formation of cellular infiltration, maintenance of inflammation, and atrophy. During inflammatory processes a huge amount of free radicals are released as well as proteolytic enzymes, which cause tissue damage $[10,15]$. Currently, new substances potent in inhibition of such process are being intensively investigated. An attempt to estimate such a potential of flavonoids was undertaken in this study. Flavone and its derivatives can inhibit different pro-inflammatory mediators and enzymes as well as scavenge free radicals [22]. Hypothetically, flavonoids can inhibit IL-8 in two different ways: direct and indirect. Its direct influence on proinflammatory generation probably depends on simple anti-microbial effect. Such a property has been proven for many flavonoids, e.g. flavone [24]. Some authors have exposed its strong antiH. pylori property. This observation has not been confirmed in this study; only galangin $(>60 \mu \mathrm{M})$ has inhibited

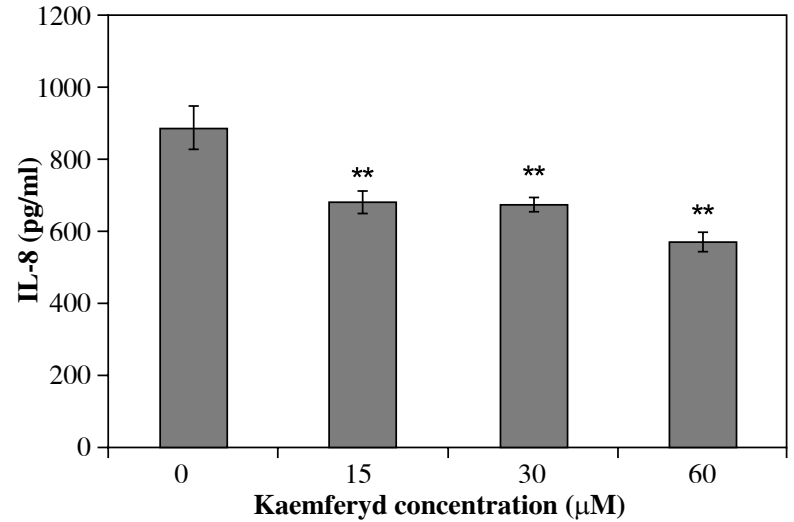

Fig. 7. Interleukin-8 release by AGS cells infected with H. pylori incubated with kaemferyd. Results shown as mean $\pm \mathrm{SD}(* * t$-Student test, $p<0.001)$

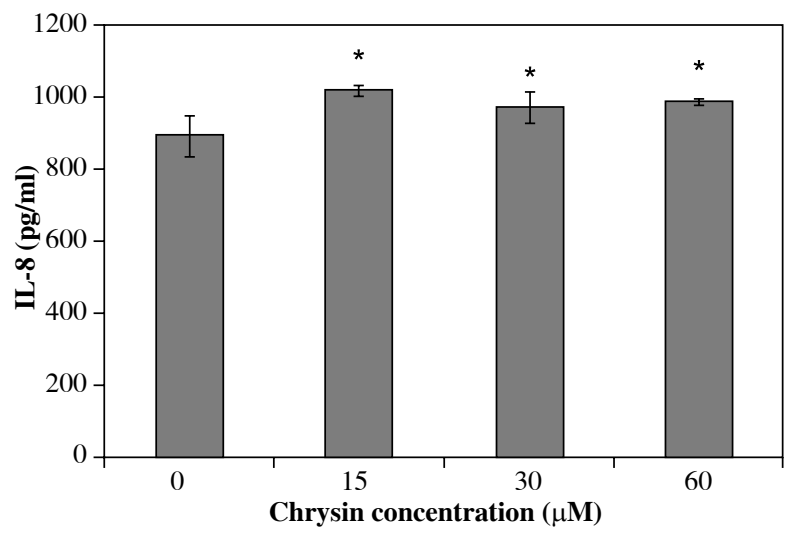

Fig. 8. Interleukin-8 release by AGS cells infected with $H$. pylori incubated with chrysin. Results shown as mean $\pm \mathrm{SD}(* * t$-Student test, $p<0.001)$

a growth of $H$. pylori. Sufficient inflammatory stimulation depends on direct contact between sensitive cells and virulent bacterial pathogens. The increase of IL-8 expression on transcription level by $H$. pylori has been proven [18]. The data obtained in this study have shown that almost all flavone derivatives were unable to inhibit $H$. pylori, whereas production of IL- 8 by activated AGS cells incubated with flavonoids has been inhibited. This observation suggests that this phenomenon depends on interaction between stimulated AGS cells and flavone derivatives (indirect action). This study has shown only basal levels of IL-8 released $(57.8 \pm 8.0 \mathrm{pg} / \mathrm{ml})$. The amount of IL- 8 released significantly increased after incubation of AGS cells with H. pylori suspension $(894.6 \pm 58.9 \mathrm{pg} / \mathrm{ml})$. All flavone derivatives except chrysin have shown IL- 8 inhibition. The strongest inhibitory effect of galangin, proportional to its 
concentration, was observed (22\% of the inhibitory ratio for $15 \mu \mathrm{M}$ and $71.9 \%$ of the inhibitory ratio for $60 \mu \mathrm{M}$ ). This observation suggests an inhibitory potential of flavonoids on different inflammatory mediators' genes expression in activated cells. It is known that NF- $\kappa \mathrm{B}$ is an important transcription factor, which is involved in the regulation of genes expression, encoding adhesive molecules and cytokines such as IL-8. When cells are stimulated by proinflammatory cytokines, reactive oxygen species, or microorganisms specific kinases phosphorylate inhibitor $\kappa \mathrm{B}(\mathrm{I}-\kappa \mathrm{B})$, causing its rapid degradation by proteasomes. This release from I- $\kappa \mathrm{B}$ activates NF- $\kappa \mathrm{B}$ and its translocation to the nucleus, where it binds to specific consensus sequences in the promoter regions of target genes (for IL-1, IL-2, IL-6, IL-8, and TNF) and mediates gene transcription [7, 25]. Helicobacter pylori has been shown to induce the activation of NF- $\mathrm{BB}$ in human gastric cancer cell lines, which is followed by increased proinflammatory cytokine expression, consistent with the NF- $\mathrm{BB}$ up-regulation of gene transcription. In accordance with the results of in vitro studies, several studies have shown that NF- $\kappa \mathrm{B}$ activity and expression of proinflammatory cytokines are increased in $H$. pylori associated gastritis. Antioxidant substances can inhibit IL-8 gene expression [26]. Nuclear factor $\kappa \mathrm{B}$ activity depends on cellular red-ox state [27]. Exogenous and endogenous antioxidants modulating redox state change also depending on genes transcription. Earlier studies have shown inhibitory effect of flavonoids on NF- $\kappa B$ activation [9, 22, 24, 27]. Many different mechanisms lead to NF- $\kappa$ B inhibition, such as suppression of $\mathrm{I} \kappa \mathrm{B} \alpha$ phosphorylation, modulation of mitogen activated protein kinase activity, as well as mitogen-activated protein kinase 1 (MEKK 1) or NF- $\kappa \mathrm{B}$-inducing kinase (NIK). All data obtained in this study suggest anti-inflammatory potential of investigated flavonoids, which is dependent on efficient inhibition of IL-8 release by AGS cells activated by $H$. pylori associated infection. Flavonoids used in therapy as auxiliary substances can be helpful in suppression of inflammatory reaction as well as protective and scavenging activity against free radicals [24]. Selected diet supplements could be important protective anti-inflammatory and anti-cancer factors intensifying standard triple therapy against $H$. pylori; what is more, they do not express any side effects at the same time.

\section{The authors declare no conflict of interest.}

\section{References}

1. Zhang MJ, Meng FL, Ji XY, et al. (2007): Adherence and invasion of mouse adapted $\mathrm{H}$. pylori in different epithelial cell lines. World J Gastroenterol 13: 845-850.

2. Marshall BJ, Warren JR (1984): Unidentified curved bacilli in the stomach of patients with gastritis and peptic ulceration. Lancet 1: 1311-1315.
3. Williams MP, Pounder RE (1999): Helicobacter pylori: from the begin to the malignant. Am J Gastroenterol 94: 11-16.

4. Hammond CE, Beeson C, Suarez G, et al. (2015): Helicobacter pylori virulence factors affecting gastric proton pump expression and acid secretion. Am J Physiol Gastrointest Liver Physiol 309: 193-201.

5. Rimbara E, Mori S, Kim H, et al. (2013): Role of $\gamma$-glutamyltranspeptidase in the pathogenesis of Helicobacter pylori infection. Microbiol Immunol 57: 665-673.

6. Kaji T, Ishihara S, Ashizawa N, et al. (2002): Adherence of Helicobacter pylori to gastric epithelial cells and mucosal inflammation. J Lab Clin Med 139: 244-250.

7. Kim SG, Kim JS, Kim JM, et al. (2005): Inhibition of pro-inflammatory cytokine expression by NF- $\mathrm{kB}$ (p65) antisense oligonucleotide in Helicobacter pylori infected mice. Helicobacter 10: 559-566.

8. Siddique I, Al-Qabandi A, Al-Ali J, et al. (2014): Association between Helicobacter pylori genotypes and severity of chronic gastritis, peptic ulcer disease and gastric mucosal interleukin-8 levels: Evidence from a study in the Middle East. Gut Pathog 6; 41.

9. Skiba M, Szliszka E, Kunicka M, et al. (2011): Effect of ethanol extract of propolis (EEP) on interleukin 8 release by human gastric adenocarcinoma cells (AGS) infected with Helicobacter pylori. Cent Eur J Immunol 36: 65-69.

10. Crabtree JE, Covacci A, Farmery SM, et al. (1995): Helicobacter pylori induced interleukin-8 expression in gastric epithelial cells is associated with CagA positive phenotype. J Clin Pathol 48: 41-45.

11. Clyne M, Dolan B, Reeves EP (2007): Bacterial factors that mediate colonization of the stomach and virulence of Helicobacter pylori. FEMS Microbiol Lett 268: 135-143.

12. Hatekeyama M, Brzozowski T (2006): Pathogenesis of Helicobacter pylori infection. Helicobacter 11 (suppl. 1): 14-20.

13. Sikora A, Grzesiuk E (2007): Heat shock response in gastrointestinal tract. J Physiol Pharm 58 Suppl 3: 43-62.

14. Targosz A, Pierzchalski P, Krawiec A, et al. (2006): Helicobacter pylori inhibits expression of heat shock protein 70 (HSP70) in human epithelial cell line. Importance of CAG A protein. J Physiol Pharmacol 57: 265-278.

15. Sharma SA, Tummuru MK, Miller GG, Blaser MJ (1995): Interleukin-8 response of gastric epithelial cell lines to Helicobacter pylori stimulation in vitro. Infect Immun 63: 16811687.

16. Ulmer HJ, Beckerling A, Gatz G (2003): Recent use of proton pump inhibitor-based triple therapies for the eradication of H. pylori: a broad data review. Helicobacter 8: 95-104.

17. Marín L, Miguélez EM, Villar CJ, Lombó F (2015): Bioavailability of dietary polyphenols and gut microbiota metabolism: antimicrobial properties. Biomed Res Int 905215. doi: $10.1155 / 2015 / 905215$

18. Isomoto H, Mizuta Y, Miyazaki M, et al. (2000): Implication

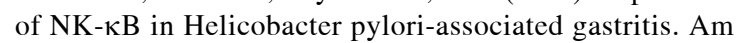
J Gastroenterol 95: 2768-2776.

19. Slomiany BL, Slomiany A (2007): Interference by leptin with Helicobacter pylori lipopolysaccharide-induced cytosolic phospholipase A2 activation in gastric mucosal cells. J Physiol Pharmacol 58: 117-130.

20. Krol W, Shani J, Czuba Z, Scheller S (1992): Modulating luminol-dependent chemiluminescence of neutrophils by flavones. Z Naturforsch C 47: 889-892. 
21. Krol W, Czuba Z, Scheller S, et al. (1993): Structure-activity relationship in the ability of flavonols to inhibit chemiluminescence. J Ethnopharmacol 41: 121-126.

22. Król W, Czuba ZP, Threadgill MD, et al. (1995): Inhibition of nitric oxide (NO*) production in murine macrophages by flavones. Biochem Pharmacol 50: 1031-1035.

23. Marshall BJ (1994): Helicobacter pylori. Am J Gastroenterol 89: 116-128.

24. Zayachkivska OS, Konturek SJ, Drozdowicz D, et al. (2005): Gastroprotective effects of flavonoids in plant extracts. J Physiol Pharm 56 Suppl 1: 219-231.

25. Barnes PJ, Karin M (1997): Nuclear factor- $\kappa B$ : a pivotal transcription factor in chronic inflammatory diseases. N Engl J Med 336: 1066-1071.

26. Keates S, Hitti YS, Upton M, et al. (1997): Helicobacter pylori infection activatives NF-kB in gastric epithelial cells. Gastroenterol 113: 1099-1109.

27. Sharma SA, Tummuru MK, Blaser MJ, Kerr LD (1998): Activation of IL- 8 gene expression by Helicobacter pylori is regulated by transcription factor nuclear factor-kappa B in gastric epithelial cells. J Immunol 160: 2401-2407. 